\title{
Epidemiological and Clinical Aspects of Cholera During the 2016 Epidemic in Bangui
}

\author{
Tékpa Gaspard $^{1,2}$, Diemer Henri Saint-Calvaire ${ }^{2}$, Fikouma Valentin $^{2,3}$, Service Georges ${ }^{2}$, \\ Kalthan Ernest ${ }^{4}$, Wili-Koé Prince ${ }^{1}$, Camengo Police Serges Magloire ${ }^{3,5}$ \\ ${ }^{1}$ Department of Infectious Diseases, CHU de l'Amitié, Bangui, Central African Republic. \\ ${ }^{2}$ Faculty of Health Sciences, University of Bangui, Central African Republic. \\ ${ }^{3}$ Department of Internal Medicine, CHU Communautaire, Bangui, Central African Republic \\ ${ }^{4}$ Ministry of Health, Bangui, Central African Republic. \\ ${ }^{5}$ Department of Hepato-Gastroenterology and Internal Medicine, Bangui, Central African Republic.
}

*Corresponding Author: Tékpa Gaspard, Department of Infectious Diseases, CHU de l'Amitié, Bangui, Central African Republic.. Email: tekpagaspard@yahoo.com

\begin{abstract}
Introduction: Cholera is rampant in the Central African Republic in an epidemic way. The objective of our study was to describe the epidemiological and clinical characteristics of cholera during the 2016 outbreak in Bangui.
\end{abstract}

Methodology: We conducted a retrospective study covering the period from August 1, 2016 to October 31, 2016 at the Epidemic Treatment Center in Bangui. The study included suspected cases and confirmed cases of cholera. An anonymous questionnaire collected socio-demographic, clinical, biological and therapeutic data that was captured and analyzed using Epi Info 7 software.

Results: A total of 106 patients were admitted to the Epidemic Scare Centre, 54 of whom were men (50.94\%) giving a sex ratio of 1.04. The average age was 22-17 years. Students accounted for $34.43 \%$ of the workforce. The most affected neighbourhoods were Bongossoua Island (11.32\%), Ouango (11.32\%) and Benzvi (6.60\%) located respectively in the second, seventh and fifth boroughs of Bangui. Two patients (1.89\%) were referred from the site of the displaced from the airport located in the 5th borough. In the Benzvi district of the 5th borough, four members of a household were affected by the disease. Among patients, 20 (20.80\%) have shown clinical signs after contact with a case of cholera. The average time to take care was 1.35 to 1.33 days. The main clinical signs were dehydration (100\%), diarrhea (96.23\%), vomiting (82.08\%), thirst (79.25\%), asthenia (64.15\%), cramps (46.23\%) abdominal pain (28.30\%). Dehydration was mild moderate and severe in $13.20 \%, 67.90 \%$ and $18.90 \%$ of cases respectively. Treatment was based on rehydration and antibiotic therapy. Children under five received zinc supplementation for 10 days in addition to rehydration. The case fatality rate was $2.80 \%$.

Conclusion: The emergence and spread of cholera cases in urban areas suggests that hygiene and sanitation measures are still inadequate. Preventive measures must be put in place to prevent or control cholera episodes in the future.

Keywords: Cholera, epidemiology, clinic, Bangui, Central African Republic.

\section{INTRODUCTION}

Cholera is an acute diarrheal disease of bacterial origin, caused by the ingestion of food or water contaminated with the bacillus Vibrio cholerae. It is a strictly human disease, caused by bacteria belonging to the serogroups O1 and O139 of the species Vibrio cholerae. It is a global public health problem. Africa is the most affected continent and accounts for more than $50 \%$ of cases. In 2015, there were 1,72454 cases of cholera worldwide, including 1,304 deaths, representing an overall case fatality rate of $0.8 \%$ [1].

In the Central African Republic, cholera remains an epidemic disease. The fragility of the health system and the recurrence of socio-political crises across the country are thought to be factors that could trigger cholera epidemics. The last outbreak in 2016 affected communities in the south of the country along the Oubangui River bordering the Democratic Republic of Congo. It was the cause of 265 cases, 20 of which died with a fatality rate of $7.5 \%$ [2]. The 
cases of Bangui were secondary to those in the south-east of the country along the Oubangui River. To our knowledge, cholera epidemics in Central Africa are poorly documented [2]. The aim of this work was to describe the epidemiological, clinical and therapeutic aspects of cholera during the 2016 outbreak in Bangui in order to have data that could be used to improve strategies to control cholera.

\section{MethodologY}

\subsection{History of the Disease and Study Framework}

From 07 July to 05 August 2016, around 36 cases of acute watery diarrhea with severe dehydration, including 8 deaths, were recorded in the village of Mourou-fleuve, Ndjoukou subprefecture. This locality is located along the Oubangui River in the south of the Central African Republic on the border with the Democratic Republic of the Congo.

From August 05 to 09, 2016, eight other cases of acute watery diarrhea with severe dehydration, including 4 deaths were recorded in the villages Zawara and Massamba in the sub-prefecture of Damara and one case in the Brussels district in the second borough of Bangui where the first confirmed case of cholera was reported on August 8, 2016 and admitted to the Epidemic Treatment Center (ETC) in Bangui. It is not a specific center for the treatment of cholera. However, it was organized so as to have a sorting unit from which suspected cholera cases that arrive are referred to hospital wards for simple cases (mild or moderate dehydration) and for severe cases (severe dehydration).

\subsection{Type of Study, Data Collection, Entry and Analysis}

We carried out a retrospective study which covered the period from $1^{\text {st }}$ August to 31 October 2016; data were collected using an anonymous questionnaire from medical records.

For each case, socio-demographic, clinical, biological and therapeutic data were collected. We considered as a suspected case, any individual of any age who presented with acute watery diarrhea, with or without vomiting. The suspected case was becoming a confirmed case if Vibrio cholerae was isolated from the stools. We included in the study, suspected cases and confirmed cases of cholera.

The diagnosis of cholera was made from the rectal swab submitted to a direct examination followed by culture and antibiogram. After confirming the epidemic by detecting Vibrio cholerae in at least ten stool samples, the search for Vibrio cholerae in the stool was no longer systematic for all of our patients. The collected data was entered and analyzed using the Epi Info 7 software.

\section{RESUltS}

During the study period, 106 patients were admitted to the ETC, of which 54 were men $(50.94 \%)$, giving a sex ratio of 1.04 . The patients were less than 20.5 years old in half of the cases (range 6 months and 67 years) with an average age of $22 \pm 17$ years. There were 24 children under the age of 5 , or $22.64 \%$ of the total workforce. The distribution of patients by sex and age is described in Table I. The average age in men was $20.59 \pm 15.98$ years compared to $22.57 \pm 18.33$ in women with no significant difference $(p=0.55)$. The distribution of patients by profession revealed that the proportion of pupils and students represented $34.43 \%$ of cases (see Figure 1). A total of 69 patients $(65.09 \%)$ came from the $2^{\text {nd }}, 5^{\text {th }}$ and $7^{\text {th }}$ borough of Bangui. The northern periphery (Bégoua) and the southern periphery (Bimbo) of Bangui recorded a total of $11.32 \%$ of the cases. The districts most affected were Bongossoua Island (11.32\%), Ouango (11.32\%) and Benzvi (6.60\%) located respectively in the second, seventh and fifth borough of Bangui. Two patients (1.89\%) were referred from the airport internal displaced people (IDP) site in the 5th borough. In Benzvi district in the $5^{\text {th }}$ borough, four members of a household have been affected by the disease, including two children under ten years. Figure 2 describes the distribution of cases according to the period of their occurrence.

TableI. Distribution of cholera patients during the 2016 epidemic in Bangui by age range and sex.

\begin{tabular}{|l|c|c|c|c|c|c|}
\hline \multirow{2}{*}{$\begin{array}{l}\text { Age range } \\
\text { years) }\end{array}$} & \multicolumn{2}{|c|}{ Male } & \multicolumn{2}{c|}{ Feminine } & \multicolumn{2}{c|}{ Total } \\
\cline { 2 - 7 } & Number & $\mathbf{\%}$ & Number & \% & Number & \% \\
\hline$<1$ & 3 & 50,00 & 3 & 50,00 & 6 & 5.66 \\
\hline $1-4$ & 10 & 55.56 & 8 & 44.44 & 18 & 16.98 \\
\hline $5-14$ & 11 & 57.89 & 8 & 42.11 & 19 & 17.92 \\
\hline $15-24$ & 6 & 30,00 & 14 & 70,00 & 20 & 18.87 \\
\hline $25-34$ & 10 & 52.63 & 9 & 47.37 & 19 & 17.92 \\
\hline$\geq 35$ & 14 & 58.33 & 10 & 41.67 & 24 & 22.64 \\
\hline Total & 54 & 50.94 & 52 & 49.06 & 106 & 100.00 \\
\hline
\end{tabular}




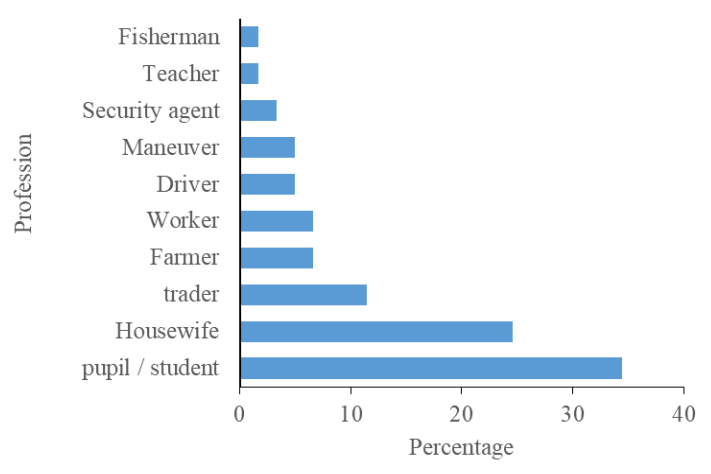

Figure1. Distribution of patients admitted for cholera at the Bangui Epidemic Treatment Center according to their profession $(N=106)$.

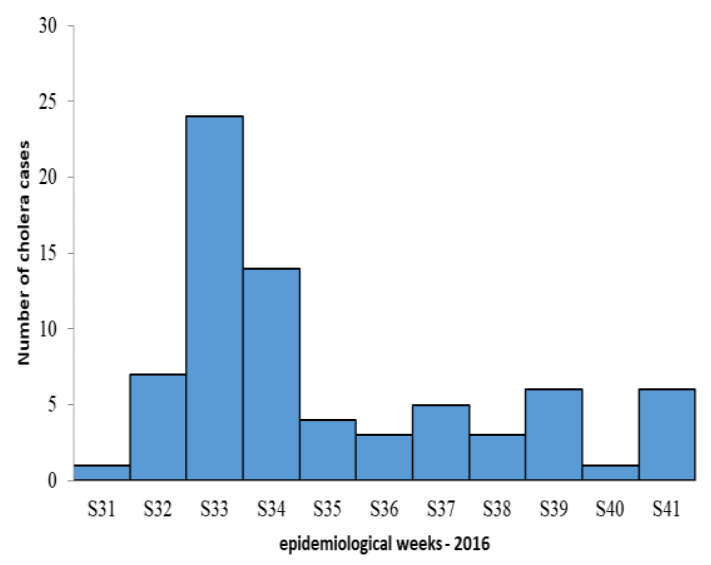

Figure2. Evolution of cholera cases during the 2016 epidemic in Bangui $(N=74)$

In all, 20 out of 96 patients (20.80\%) presented clinical signs after being in contact with a case of cholera. The period between the onset of symptoms and that of management was specified in 74 cases. The mean time to care was $1.35 \pm 1.33$ days, the median was one day with extremes of 0 and 5 days. The main clinical signs were dehydration (100\%), diarrhea (96.23\%), vomiting (82.08\%), thirst (79.25\%), asthenia $(64.15 \%)$, cramps $(46.23 \%)$ and abdominal pain $(28.30 \%)$. Dehydration was mild in 14 patients $(13.20 \%)$, moderate in 72 (67.90\%) and severe in 20 patients (18.90\%).

The median length of stay at the treatment center was one day with extremes of 0 and 6 days. It was 1 day in mild or moderate forms and 1.5 days in severe forms. Biologically, the coproculture carried out on 20 stool samples taken by rectal swab showed the presence of $V$. cholerae 0139 in $100 \%$ of the cases. Treatment was based on rehydration and antibiotic therapy. Oral rehydration with the WHO rehydration solution was proposed as first-line treatment in cases of mild or moderate dehydration and as a parenteral relay in the event of severe dehydration whose treatment was based on Ringer's lactate solution. Children under the age of five received zinc supplementation for 10 days in addition to rehydration. Antibiotic therapy with ciprofloxacin for three days or doxycycline as a single dose was administered in the moderate or severe form. The evolution was marked by healing in 103 patients or $97.20 \%$; the case fatality rate was $2.80 \%(3 / 106)$.

\section{DISCUSSION}

Through this study, we have described the epidemiological and clinical characteristics of cholera during the 2016 epidemic in Bangui. Cholera remains an important cause of acute diarrhea in developing countries [3]. It is more and more prevalent in African urban environments in an epidemic or endemic manner. Outbreaks were reported in Dakar from 2004 to 2006 [4], in Conakry in 2012 [5]. The epidemic of Bangui had occurred in the middle of the rainy season in August 2016. It was limited in time, between the $31^{\text {th }}$ and $41^{\text {th }}$ epidemiological week. The 2016 epidemic affected all age groups including children under the age of one. However, we noted a predominance in young people. Both sexes were affected in similar proportions (sex ratio = 1.04). A sex ratio equal to 1 was reported during a cholera epidemic in Benin in 2011 [6]. All social strata have been affected by the epidemic. However, pupils, students and housewives accounted for more than half of the cases. After the confirmation of the first case, the disease had spread very quickly in the neighborhoods along the river and some densely populated neighborhoods where hygienic conditions were precarious. Within a few days, the disease had spread and put most of Bangui's districts and peripheral areas at risk. Despite a high concentration of people on the IDP sites during the epidemic, only two cases were detected at the IDP site at the airport. This situation would be linked to strict compliance with the preventive measures put in place as soon as the epidemic was declared, which were based on awareness-raising, strengthening the availability of drinking water, the use of chlorine solution for hand washing or the disinfection of contaminated surfaces and objects of the sick. Indeed, the predominant route of cholera transmission is of the fecal-oral type.

The main mode of cholera transmission during an epidemic is to ingest water or food 
contaminated with faeces containing $V$. cholerae. Often, multiple modes of fecal-oral transmission canco-exist and accelerate the spread of the disease, depending on the degree of overcrowding as well as water, sanitation and hygiene practices [7]. Cholera cases had occurred between the $31^{\text {th }}$ and $41^{\text {th }}$ epidemiological weeks for a total duration of 11 weeks. Examination of the epidemic curve shows that most cases occurred within the first four weeks of the onset of the outbreak, then the frequency of the disease declined until the end of the epidemic. This suggests that the transmission of the disease would have occurred from a common point source, especially at the beginning and then the spread would be from person to person.

Vomiting and choleriform type diarrhea were the main signs, observed in $95 \%$ and $100 \%$ of the cases, respectively. These digestive disorders were complicated by severe dehydration in about two out of five patients. Abdominal pain and muscle cramps were common and have been reported in the literature; they are linked to ionic disorders and in particular to hypokalemia [5]. Our results agree with the data from the literature that the most frequent clinical manifestations during cholera are diarrhea, dehydration, vomiting and abdominal cramps [8].

The cholera fatality rate during the 2016 Bangui epidemic appears to be higher $(2.8 \%)$ than the average of $1.3 \%$ reported in Africa in 2015 [1]. This case fatality rate varies widely from country to country, ranging from $0 \%$ (Burundi, Zimbabwe) to $7.8 \%$ (Mozambique). It is similar to that observed in Southern Sudan $(2.6 \%)$ or in Togo $(2.9 \%)$ [1].

\section{CONCLUSION}

The 2016 cholera epidemic in Bangui was secondary to that which occurred along the Oubangui River in the south-east of the country. It concerned all age groups with predominantly affected young people. The mild and moderate forms were the most frequent. The lethality was low, probably because of early case management based on rehydration and hygiene and sanitation measures implemented from the start of the epidemic. These data suggest that hygiene and sanitation measures are still inadequate. Preventive measures must be put in place to prevent or control cholera episodes in the future.

\section{REFERENCES}

[1] WHO. Choléra, 2015. Weekly epidemiological record 2016, 38: 433-440

[2] Cholera Platform. Cholera: Situation of Cholera in West and Central Africa. http://www. Plateforme cholera.info/ attachments/ article/ 292/WCA\%20Cholera_Update_W38.pdf.

[3] Tamang MD, Sharma N, Makaju RK, Sarma AN, Koju R, Nepali N, et al . An outbreak of El Tor cholera in Kavre district, Nepal. Kathmandu Univ Med J. 2005; 3 (2): $138-42$.

[4] Manga NM, Ndour CT, Diop SA, Dia NM, KaSall R, Diop BM, et al. Le choléra au Sénégal de 2004 à 2006 : les enseignements d'épidémies successives. Med Trop 2008; 68 : 589-592.

[5] Sako FB, Traore' F, Camara MK, Sylla M, Bangoura EF, Balde O. Le choléra chez la femme enceinte : cas de l'épidémie de 2012 au centre de référence de l'hôpital national Donka à Conakry Med Sante Trop 2016 ; 26 : 199202.

[6] Gbary AR, Sossou RA, Dossou JP, Mongbo V, Massougbodji A. Les déterminants de la faible létalité de l'épidémie de choléra dans le littoral au Bénin en 2008. Santé Publique 2011;5 (23) :345-358. DOI 10.391 7/spub.115.0345

[7] Unicef. Guide pratique de lutte contre le choléra. Edition 2013. https://www.unicef.org/ french /cholera_ toolkit/Document_ principal_ guide_pratique_de_lutte_contre_le_cholera.pdf

[8] Kuna A, Gajewski M. Cholera - the new strike of an old foe. Int Marit Health 2017; 68, 3: $163-167$.

\footnotetext{
Citation: Tékpa Gaspard, et al, Epidemiological and Clinical Aspects of Cholera During the 2016 Epidemic in Bangui ARC Journal of Public Health and Community Medicine. 2019; 4(4):5-8. DOI: dx.doi.org/10.20431/ 2456-0596.0404002.
}

Copyright: () 2019 Authors. This is an open-access article distributed under the terms of the Creative Commons Attribution License, which permits unrestricted use, distribution, and reproduction in any medium, provided the original author and source are credited. 